\title{
Contralateral Prophylactic Mastectomy Improves Survival Only Marginally in Patients with Unilateral Triple-Negative Breast Cancer: A Cohort Study Based on SEER Database
}

\section{Pengcheng Yang}

Wuhan University https://orcid.org/0000-0002-1047-8054

Yuxin Chu

Wuhan University Renmin Hospital

Qian Li

Wuhan University Renmin Hospital

Tianyu Lei

Wuhan University Renmin Hospital

Jia Song

Wuhan University Renmin Hospital

\section{Tingting Ning}

Wuhan University Renmin Hospital

Qinyong Hu ( $\sim$ rm001223@whu.edu.cn )

Wuhan University Renmin Hospital

\section{Research}

Keywords: Breast Neoplasms, Prophylactic Mastectomy, Survival Analysis, Triple Negative Breast Neoplasms

Posted Date: September 21st, 2021

DOI: https://doi.org/10.21203/rs.3.rs-900438/v1

License: (c) (i) This work is licensed under a Creative Commons Attribution 4.0 International License. Read Full License

Version of Record: A version of this preprint was published at Clinics in Oncology on October 20th, 2021. See the published version at https://doi.org/10.25107/2474-1663-v6-id1868. 


\section{Abstract}

Background: The effect of contralateral prophylactic mastectomy (CPM) on the survival rate of triple-negative breast cancer (TNBC) patients is still controversial. The purpose of this study was to confirm whether unilateral TNBC patients benefit from CPM.

Methods: 10006 patients with unilateral TNBC in the Surveillance, Epidemiology and End Results (SEER) database were enrolled in this study, propensity score matching (PSM) was applied to balance patient assignments. After PSM,3039 pairs of patients were divided into a CPM group and no-CPM group, respectively. All the patients have undergone total mastectomy or radical mastectomy. Cox proportional hazards regression models were used to evaluate overall survival (OS) and breast cancer-specific survival (BCSS) of the two groups. Subgroup analysis was introduced to exclude the effect of confounding factors. To identify potential variables for prognosis, Kaplan-Meier survival analysis and Cox regression analysis were used and were presented by Kaplan-Meier curve and forest plot separately.

Results: With a median follow-up time of 34.5months (IQR 1-83 months), the estimated 5-year BCSS rates for patients in the CPM group and the no-CPM group were $81.96 \%$ and $78.71 \%$, the 5 -year OS rates were $80.10 \%$ and $75.05 \%$, respectively. CPM improved the BCSS (hazard ratio $[\mathrm{HR}]=0.79 ; 95 \%$ confidence interval $[\mathrm{Cl}]=0.69-0.90, \mathrm{p}=0.001)$ and OS (HR= $0.74 ; 95 \% \mathrm{Cl}=0.66-0.84, \mathrm{p}<0.001)$ of unilateral TNBC patients. Univariate subgroup analyses revealed that there was no significant difference in survival time for patients in stage N3 who underwent CPM or not ( $p>0.05)$.

Conclusions: CPM only limitedly improved BCSS and OS in patients with unilateral TNBC undergoing total mastectomy or radical mastectomy and was not recommended for stage N3 patients.

\section{Introduction}

Triple-negative breast cancer (TNBC) refers to a heterogeneous collection of breast cancer that lacks the expression of estrogen receptor (ER), progesterone receptor (PR), and human epidermal growth factor Receptor 2 (HER2), accounting for $12-17 \%$ of all breast cancers $(1,2)$. According to WHO statistics in 2018 , the incidence rate of breast cancer today is nearly the same as that of lung cancer (11.6\% of the total cases) in both sexes combined, accounting for almost 1 in 4 cancer cases among women(3). TNBC tends to be biologically aggressive and with a lack of commonly utilized targeting agents, which is often associated with a worse prognosis and tends to relapse earlier compared with other subtypes of breast cancer $(1,4-6)$. About $1-4 \%$ of patients with unilateral breast cancer developed contralateral breast cancer (CBC) within 5-12 years and the risk increases by $0.5 \%$ to $0.75 \%$ per year, in triple-negative disease cases, the risk of CBC was increased steadily over time(7-9).

The risk of death for bilateral breast cancer was approximately 2.50 times higher than unilateral breast cancer(10). Therefore, reducing the incidence of contralateral breast cancer will be helpful to reduce the mortality of breast cancer patients.

Plenty of studies have demonstrated that breast cancer patients could obtain a survival advantage and decrease cancer-related anxiety from contralateral prophylactic mastectomy (CPM) (11-17). However, CPM is usually more applicable to breast cancer patients with BRCA mutations because they have a higher risk of developing contralateral breast cancer(CBC), this risk was higher in BRCA1 compared to BRCA2 carriers(18). A retrospective study demonstrated that among patients with BRCA mutations, $57.1 \%$ have the clinical TNBC subtype (19). Despite the use of CPM has been increased in breast cancer patients these years, only a limited number of studies focused on CPM in $\operatorname{TNBC}(20,21)$.

In this study, we used the Surveillance, Epidemiology, and End Results (SEER) database to evaluate the impact of CPM on the clinical outcome of unilateral TNBC patients undergoing total mastectomy or radical mastectomy.

\section{Patients And Methods}

\subsection{Patient selection}

All data used in the current study were obtained from Surveillance, Epidemiology, and End Results (SEER) 18 registries Custom Data (with additional treatment fields) of the National Cancer Institute in the United States. We used SEER ${ }^{\star S}$ tat version 8.3.6 to download data files directly. No informed consent or institutional review board approval was required in the present study due to the publicavailable data of SEER. The inclusion criteria were:(a) Female patients diagnosed with breast cancer between 2010 and 2016.

Page 2/18 
(b)Unilateral single primary stage M0 triple-negative breast cancer (TNBC) subtype. (c)Patients undergoing total mastectomy or radical mastectomy. Patients missing any of the following information were excluded: marital status, race recode, age at diagnosis, AJCC TNM stage, tumor size, the status of regional nodes, radiation recode, vital status recodes, and follow-up. Patients before 2010 or after 2016 were excluded because these patients were not recorded in SEER 18 registries Custom Data. People with postoperative survival time of less than one month were also excluded. The selection process was shown in Fig 1.

\subsection{Data collection}

The following variables were collected from all patients: age at diagnosis, marital status, race recode, laterality, grade, AJCC TNM stage, tumor size, regional nodes status, surgery type, radiation recode, chemotherapy recode, survival months, and vital status recode. In the study, breast cancer-specific survival (BCSS) was used as the primary study outcome and was calculated from the date of diagnosis to the date of death caused by breast cancer. The secondary endpoint was overall survival (OS) (time from diagnosis to death from any cause).

\subsection{Statistical analysis}

The main demographic data include age at diagnosis, marital status, race recode. Age was divided into three subgroups $(<40,40-59$ and $\geq 60$ years). Marital status comprised married and not married (divorced, widowed, single, and separated). Race categories included white, black, and other (American Indian/AK Native, Asian/Pacific Islander). Tumor features included TNM stage, tumor size, and regional nodes status. Treatment methods were classified into surgery (radical mastectomy and total mastectomy), chemotherapy, and radiotherapy. Propensity score matching (PSM) was applied to balance patient assignments to properly assess the effects of CPM. The Chi-square test was used to evaluate the differences between the variables. OS and BCSS were estimated by the Kaplan-Meier method, and differences between groups were assessed using the log-rank test. Univariate and multivariate Cox proportional hazards regression models were performed to identify the independent factors with a significant impact on patient survival. Hazard ratios (HRs) and 95\% confidence intervals (Cls) were calculated for each prognostic factor. All the statistical analyses were performed using SPSS statistical software, version 26.0 (SPSS, Chicago, IL, USA). A two-tailed P $<0.05$ was considered statistically significant.

\section{Results}

\subsection{Patient characteristics}

Based on the inclusion and exclusion criteria, 10006 patients were included in our study, of which 3791(37.9\%) patients underwent CPM while 6215(62.1\%) patients did not undergo contralateral prophylactic mastectomy(no-CPM). Most variables showed a significant difference between the two groups $(p<0.05)$, except for laterality and radiotherapy $(p>0.05)$. Compared with those patients who did not receive CPM, patients in the CPM group were more $<60$ years old $(90.2 \%$ vs $62.0 \%)$, more white race $(80.2 \%$ vs $67.9 \%)$, more married (65.2\% vs $52.4 \%)$, and more patients underwent total mastectomy (65.0\% vs $49.4 \%)$. There was little difference in proportion distribution among other variables. After PSM, a total of 3039 pairs of cases were matched. We analyzed the baseline data of each subgroup and found that there was no significant statistical difference between these two groups besides the $\mathrm{N}$ stage. Table 1 summarizes the demographic and clinical characteristics of the patients in both groups before and after PSM.

\subsection{Survival analysis of all population}

The median follow-up time was 34.5months (IQR 1-83 months). 860(14.1\%) patients died from breast cancer specifically, 378 (12.4\%) in the CPM group and 482(15.8\%) in the no-CPM group. The estimated 5-year breast cancer-specific survival (BCSS) rates for patients in the CPM group and no- CPM group were $81.96 \%$ and $78.71 \%$, the 5 -year overall survival (OS) rates were $80.10 \%$ and $75.05 \%$, respectively. The Kaplan Meier analysis revealed that patients who underwent CPM had better survival than the patients in the no-CPM 
group in both BCSS and OS (both log-rank $p<0.005$, Fig.2). Univariate and multivariate Cox proportional hazard models were estimated to investigate the effect of risk factors on BCSS and OS.

In the univariate analysis of BCSS, all factors were associated with BCSS in TNBC patients compared with each reference group, with the exclusion of laterality $(P>0.05)$. All relevant factors were integrated into the multivariate Cox regression analysis of BCSS. The multivariate analysis demonstrated that patients of grade IV, more advanced T stage(T3-T4), stage N3, tumor size $>50 \mathrm{~mm}$ and more regional nodes positive resulted in an adverse survival outcome of TNBC $(H R>1, P<0.05)$. CPM, other races, chemotherapy, and midlife (40-59 years old) were protective factors for women with $T N B C(H R<1, P<0.05)$. The results of the multivariate analysis were shown in Table 2.

The univariate Cox regression analysis of overall survival (OS) indicated laterality and radiotherapy were not significantly associated with OS. According to previous clinical experience, radiotherapy was one of the conventional treatment protocols for TNBC, so radiotherapy was also included in the multivariate Cox proportional hazards model. Results showed that unmarried, grade IV, more advanced T stage(T3-T4), stage N3, larger tumors, and more regional nodes positive were proved to be positively associated with breast cancer-specific mortality ( $\mathrm{HR}>1, \mathrm{P}<0.05)$. Patients in CPM, chemotherapy, midlife (40-59 years old), and the other race (American Indian/AK Native, Asian/Pacific Islander) group experience better survival ( $H R<1, P<0.05)$. CPM was shown to be the factor associated with improved cancer outcomes in both univariate and multivariate analysis of OS (univariate analysis: $\mathrm{HR}=0.78, \mathrm{Cl}=0.69-0.88$, $\mathrm{P}<0.001$, and multivariate analysis: $\mathrm{HR}=0.74, \mathrm{Cl}=0.66-0.84, \mathrm{P}<0.001)$, detailed in Table 3 .

In conclusion, these analyses suggested that TNBC patients undergoing radical mastectomy or total mastectomy could benefit from CPM and chemotherapy. K-M survival curve for BCSS and OS was shown in Fig. 2.

\subsection{Subgroup analysis}

The baseline of stage $\mathrm{N}$ remained unbalanced after propensity score matching (Table 1), therefore stage $\mathrm{N}$ may be a potential confounder and was included in the subgroup analysis. According to the results of BCSS and OS multivariate Cox survival analysis, the N stage was divided into N0-N2 group and N3 group because there was no significant difference between N1 - N2 patients and N0 patients (log-rank P>0.05). K-M survival curves (Fig.3 and Fig.4) showed that stage N0-N2 patients in the CPM group had superior BCSS and OS than those in the no-CPM group (log-rank $\mathrm{P}<0.05$ ), while stage N3 patients in both groups did not derive survival benefit from CPM (log-rank P>0.05).

The subgroup analyses were illustrated by forest plots of HRs, which revealed that factors positively associated with the prognosis of TNBC patients included CPM, chemotherapy, and middle age (40-59 years old). These two forest plots also more visualize that higher tumor stage (stage T3-T4 and N3), larger tumor tissue (tumor size $>50 \mathrm{~mm}$ ), and more regional positive lymph nodes were risk factors for TNBC patients. (Fig.5 and Fig.6).

\section{Discussion}

It is still controversial that whether patients with TNBC can get survival benefits from the contralateral prophylactic mastectomy. In this study, the clinical characteristics of patients with TNBC and the effect of CPM on the prognosis of TNBC patients were analyzed retrospectively, which was based on a large population from the SEER database. Our results suggest that patients with unilateral TNBC undergoing total mastectomy or radical mastectomy may obtain survival benefits from CPM.

In a previous cohort study of 1325 TNBC patients, Adkins et al. (2011) investigated the effect of surgical approaches on the prognosis in TNBC patients(22). This study reported the 5-year overall survival rate (OS) of patients undergoing breast-conserving therapy (BCT) and mastectomy was $74 \%$ and $63 \%$, respectively. Our study showed that patients undergoing CPM have a higher 5-year overall survival rate (OS) of $80.10 \%$, and we took a more rigorous manner to eliminate the possible effect of confounders.

Reducing recurrence is one of the ways to reduce the risk of death in this special population. Several studies have shown that female TNBC patients are at a higher risk of relapse and have an associated poorer prognosis compared with those with other subtypes of breast cancer $(1,23)$, an early peak of recurrences at 3 years after diagnosis which was responsible for the poor prognosis of triplenegative breast cancer (24). CPM could prolong the BCSS of TNBC patients by decreasing the risk of subsequent contralateral breast cancer. 
In addition, TNBC complicated with occult cancer may be another reason for poor prognosis. The overall rate of occult cancer in breast cancer was about $7.1 \%$, simple total mastectomy or radical mastectomy cannot completely remove occult cancer that may coexist(25). Therefore, recurrence or progression will occur. King, TA, et al. (2015) reported a part of occult breast cancer was detected in contralateral prophylactic mastectomy specimens (26). Prophylactic resection of the contralateral breast could minimize the risk of this occult cancer. Although our study could not directly prove that CPM could increase the resection rate of occult cancer, it also indirectly showed that the expanded resection could reduce the risk of death, and we speculated that this risk might be caused by occult cancer, so further histopathological examination to verify the existence of occult cancer in the contralateral breast is necessary.

Although studies by Bedrosian, et al. (2010) (14)and Brewster et al. (27)Suggested that ER-negative or hormone receptor-negative breast cancer patients were more likely to receive benefit from CPM, their studies were not specific to the triple-negative subtype and therefore may underestimate the effect of CPM on receptor-positive patients.

In our observation, we found that not all unilateral TNBC patients could obtain a better prognosis from CPM. Unlike NO-N2 patients, there was no significant difference in survival of stage N3 patients with or without CPM (Fig.3 and Fig.4). Identifying subgroups more likely to achieve better treatment outcomes from CPM may be of great significance in choosing a more personalized approach for patients.

There are several limitations to this study, including those inherent to a retrospective observational study design. First, the study may be affected by selection bias. Second, the demographic information provided by the SEER database does not include complications and other detailed factors. The contribution of these factors to survival benefits cannot be evaluated. Third, the interval between surgery and radiotherapy and chemotherapy and the data of chemotherapy regimens may also have an impact on survival outcomes and provide important implications for clinical practice. Fourth, some studies have shown that BRCA1/2 mutation carriers with breast cancer have a high risk of contralateral disease, carriers of the BRCA1 gene mutation are more likely to develop triple-negative breast cancer, and these women usually choose to undergo contralateral mastectomy, to reduce the likelihood of recurrence $(28,29)$. However, the SEER database does not provide data on the status of BRCA1/2 mutation. Lack of availability of this information in the database limits us to evaluate the influence of these factors. Despite certain limitations, our study is a population-based study that includes a large number of unilateral TNBC patients, and the results are convincing.

\section{Conclusion}

In conclusion, our study demonstrates that CPM does improve survival in patients with unilateral triple-negative breast cancer, excluding those with stage N3, but this improvement is very limited. Therefore, clinicians should be extra cautious when choosing whether to apply CPM. Further prospective clinical trials are still needed to validate our findings.

\section{Abbreviations}

CPM - contralateral prophylactic mastectomy

TNBC - triple-negative breast cancer

SEER - the Surveillance, Epidemiology and End Results

OS - overall survival

BCSS - breast cancer-specific survival

HR - hazard ratio

$\mathrm{Cl}$ - confidence interval

PSM - propensity score matching

BCT - breast-conserving therapy

\section{Declarations}


Ethics approval and consent to participate No ethics approval, consent to participate or consent for publication was required for this study.

Consent for publication All authors are informed and consent for publication.

Funding The authors received no financial support for the research and authorship of this article.

Conflicts of interest The authors declared no conflicts of interest.

Availability of data and material All the data and material were true and availability.

Code availability Not applicable.

Authors' contributions QH, PY conceptualized the paper. PY, QL and, TL analyzed the data. The data was collected by PY, JS, TN, TL, and QL. PY and YC wrote the initial draft with all authors providing critical feedback and edits to subsequent revisions. All authors approved the final draft of the manuscript. QH is the guarantor. The corresponding authors attest that all listed authors meet authorship criteria and that no others meeting the criteria have been omitted.

\section{Acknowledgements}

The authors acknowledge the tremendous effort made by the Surveillance, Epidemiology, and End Results (SEER) database program to create the SEER database.

\section{Data access}

We obtained permission to access the SEER database under the login 15870-Nov2017. informed consent is not required to extract data from the SEER database.

\section{References}

1. Newman LA, Reis-Filho JS, Morrow M, Carey LA, King TA. The 2014 Society of Surgical Oncology Susan G. Komen for the Cure Symposium: triple-negative breast cancer. Annals of surgical oncology. 2015;22(3):874-82.

2. DeSantis CE, Ma J, Gaudet MM, Newman LA, Miller KD, Goding Sauer A, et al. Breast cancer statistics, 2019. CA: a cancer journal for clinicians. 2019;69(6):438-51.

3. Bray F, Ferlay J, Soerjomataram I, Siegel RL, Torre LA, Jemal A. Global cancer statistics 2018: GLOBOCAN estimates of incidence and mortality worldwide for 36 cancers in 185 countries. CA: a cancer journal for clinicians. 2018;68(6):394-424.

4. Li X, Yang J, Peng L, Sahin AA, Huo L, Ward KC, et al. Triple-negative breast cancer has worse overall survival and cause-specific survival than non-triple-negative breast cancer. Breast cancer research and treatment. 2017;161(2):279-87.

5. Bianchini G, Balko JM, Mayer IA, Sanders ME, Gianni L. Triple-negative breast cancer: challenges and opportunities of a heterogeneous disease. Nature reviews Clinical oncology. 2016;13(11):674-90.

6. Dawood S. Triple-negative breast cancer: epidemiology and management options. Drugs. 2010;70(17):2247-58.

7. Yoon TI, Kwak BS, Yi OV, Kim S, Um E, Yun KW, et al. Age-related risk factors associated with primary contralateral breast cancer among younger women versus older women. Breast cancer research and treatment. 2019;173(3):657-65.

8. Montgomery LL, Tran KN, Heelan MC, Van Zee KJ, Massie MJ, Payne DK, et al. Issues of regret in women with contralateral prophylactic mastectomies. Annals of surgical oncology. 1999;6(6):546-52.

9. Mose S, Adamietz IA, Thilmann C, Saran F, Pahnke R, HD Bt. [The prognosis of bilateral breast carcinoma compared to unilateral breast tumor. 5- and 10-year follow-ups]. Strahlentherapie und Onkologie : Organ der Deutschen Rontgengesellschaft [et al]. 1995;171(4):207-13.

10. Kuo WH, Yen AM, Lee PH, Chen KM, Wang J, Chang KJ, et al. Cumulative survival in early-onset unilateral and bilateral breast cancer: an analysis of 1907 Taiwanese women. British journal of cancer. 2009;100(4):563-70.

11. Peralta EA, Ellenhorn JD, Wagman LD, Dagis A, Andersen JS, Chu DZ. Contralateral prophylactic mastectomy improves the outcome of selected patients undergoing mastectomy for breast cancer. American journal of surgery. 2000;180(6):439-45. 
12. Goldflam K, Hunt KK, Gershenwald JE, Singletary SE, Mirza N, Kuerer HM, et al. Contralateral prophylactic mastectomy. Predictors of significant histologic findings. Cancer. 2004;101(9):1977-86.

13. Tuttle TM, Habermann EB, Grund EH, Morris TJ, Virnig BA. Increasing use of contralateral prophylactic mastectomy for breast cancer patients: a trend toward more aggressive surgical treatment. Journal of clinical oncology : official journal of the American Society of Clinical Oncology. 2007;25(33):5203-9.

14. Bedrosian I, Hu CY, Chang GJ. Population-based study of contralateral prophylactic mastectomy and survival outcomes of breast cancer patients. Journal of the National Cancer Institute. 2010;102(6):401-9.

15. Wong-Brown MW, Meldrum CJ, Carpenter JE, Clarke CL, Narod SA, Jakubowska A, et al. Prevalence of BRCA1 and BRCA2 germline mutations in patients with triple-negative breast cancer. Breast cancer research and treatment. 2015;150(1):71-80.

16. Lostumbo L, Carbine NE, Wallace J. Prophylactic mastectomy for the prevention of breast cancer. The Cochrane database of systematic reviews. 2010(11):CD002748.

17. Hatcher MB, Fallowfield L, Hern R. The psychosocial impact of bilateral prophylactic mastectomy: prospective study using questionnaires and semistructured interviews. BMJ (Clinical research ed). 2001;322(7278):76.

18. Valachis A, Nearchou AD, Lind P. Surgical management of breast cancer in BRCA-mutation carriers: a systematic review and metaanalysis. Breast cancer research and treatment. 2014;144(3):443-55.

19. Atchley DP, Albarracin CT, Lopez A, Valero V, Amos Cl, Gonzalez-Angulo AM, et al. Clinical and pathologic characteristics of patients with BRCA-positive and BRCA-negative breast cancer. J Clin Oncol. 2008;26(26):4282-8.

20. Stucky CC, Gray RJ, Wasif N, Dueck AC, Pockaj BA. Increase in contralateral prophylactic mastectomy: echoes of a bygone era? Surgical trends for unilateral breast cancer. Annals of surgical oncology. 2010;17 Suppl 3:330-7.

21. Lizarraga I, Schroeder MC, Weigel RJ, Thomas A. Surgical Management of Breast Cancer in 2010-2011 SEER Registries by Hormone and HER2 Receptor Status. Annals of surgical oncology. 2015;22 Suppl 3(Suppl 3):S566-72.

22. Adkins FC, Gonzalez-Angulo AM, Lei X, Hernandez-Aya LF, Mittendorf EA, Litton JK, et al. Triple-negative breast cancer is not a contraindication for breast conservation. Annals of surgical oncology. 2011;18(11):3164-73.

23. Anders CK, Carey LA. Biology, metastatic patterns, and treatment of patients with triple-negative breast cancer. Clinical breast cancer. 2009;9 Suppl 2(Suppl 2):S73-81.

24. Dent R, Trudeau M, Pritchard KI, Hanna WM, Kahn HK, Sawka CA, et al. Triple-negative breast cancer: clinical features and patterns of recurrence. Clinical cancer research : an official journal of the American Association for Cancer Research. 2007;13(15 Pt 1):4429-34.

25. Arai M, Yokoyama S, Watanabe C, Yoshida R, Kita M, Okawa M, et al. Genetic and clinical characteristics in Japanese hereditary breast and ovarian cancer: first report after establishment of $\mathrm{HBOC}$ registration system in Japan. Journal of human genetics. 2018;63(4):447-57.

26. King TA, Pilewskie M, Muhsen S, Patil S, Mautner SK, Park A, et al. Lobular Carcinoma in Situ: A 29-Year Longitudinal Experience Evaluating Clinicopathologic Features and Breast Cancer Risk. Journal of clinical oncology : official journal of the American Society of Clinical Oncology. 2015;33(33):3945-52.

27. Brewster AM, Bedrosian I, Parker PA, Dong W, Peterson SK, Cantor SB, et al. Association between contralateral prophylactic mastectomy and breast cancer outcomes by hormone receptor status. Cancer. 2012;118(22):5637-43.

28. Evans DG, Ingham SL, Baildam A, Ross GL, Lalloo F, Buchan I, et al. Contralateral mastectomy improves survival in women with BRCA1/2-associated breast cancer. Breast cancer research and treatment. 2013;140(1):135-42.

29. Lakhani SR, Van De Vijver MJ, Jacquemier J, Anderson TJ, Osin PP, McGuffog L, et al. The pathology of familial breast cancer: predictive value of immunohistochemical markers estrogen receptor, progesterone receptor, HER-2, and p53 in patients with mutations in BRCA1 and BRCA2. Journal of clinical oncology : official journal of the American Society of Clinical Oncology. 2002;20(9):2310-8.

\section{Tables}

Table 1 Baseline characteristics of TNBC patients included in this study $(n=10006 \rrbracket n=6078$ after PSM $)$ 


\begin{tabular}{|c|c|c|c|c|c|c|c|c|}
\hline \multirow[t]{3}{*}{ Variables } & \multicolumn{3}{|l|}{ Before PSM } & \multirow[t]{3}{*}{$\mathrm{p}$} & \multicolumn{3}{|l|}{ After PSM } & \multirow[t]{2}{*}{$\mathrm{p}$} \\
\hline & Total, n (\%) & $\begin{array}{l}\text { No-CPM, } \\
\mathrm{n}(\%)\end{array}$ & CPM, n (\%) & & Total, n (\%) & $\begin{array}{l}\text { No-CPM, } \\
\mathrm{n}(\%)\end{array}$ & CPM, n (\%) & \\
\hline & $n=10006$ & $\mathrm{n}=6215(62.1)$ & $\mathrm{n}=3791(37.9)$ & & $n=6078$ & $n=3039$ & $n=3039$ & \\
\hline Age & & & & $<0.001$ & & & & 0.484 \\
\hline$<40$ & $1382(13.80)$ & $490(7.90)$ & $892(23.50)$ & & $928(15.30)$ & $459(15.10)$ & $469(15.40)$ & \\
\hline $40-59$ & $5892(58.90)$ & $3364(54.10)$ & $2528(66.70)$ & & $4377(72.00)$ & 2178(71.70) & 2199(72.40) & \\
\hline$\geq 60$ & $2732(27.30)$ & $2361(38.00)$ & $371(9.80)$ & & 773(12.70) & $402(13.20)$ & $371(12.20)$ & \\
\hline Race & & & & $<0.001$ & & & & 0.734 \\
\hline White & $7261(72.60)$ & $4222(67.90)$ & $3039(80.20)$ & & $4673(76.90)$ & $2341(77.00)$ & 2332(76.70) & \\
\hline Black & 1885(18.80) & $1343(21.60)$ & $542(14.30)$ & & $1008(16.60)$ & $507(16.70)$ & $501(16.50)$ & \\
\hline Other & $860(8.60)$ & $650(10.50)$ & $210(5.50)$ & & $397(6.50)$ & 191(6.30) & $206(6.80)$ & \\
\hline Marital status & & & & $<0.001$ & & & & 0.091 \\
\hline Married & $5728(57.20)$ & $3256(52.40)$ & $2472(65.20)$ & & $3766(62.00)$ & 1915(63.00) & $1851(60.90)$ & \\
\hline Not Married & $4278(42.80)$ & 2959(47.60) & 1319(34.80) & & 2312(38.00) & 1124(37.00) & 1188(39.10) & \\
\hline Laterality & & & & 0.451 & & & & 0.739 \\
\hline Left & $5050(50.50)$ & $3155(50.80)$ & 1895(50.00) & & $3037(50.00)$ & $1525(50.20)$ & $1512(49.80)$ & \\
\hline Right & $4956(49.50)$ & $3060(49.20)$ & $1896(50.00)$ & & $3041(50.00)$ & $1514(49.80)$ & $1527(50.20)$ & \\
\hline Grade & & & & 0.003 & & & & 0.713 \\
\hline I & $142(1.40)$ & $96(1.50)$ & $46(1.20)$ & & $79(1.30)$ & $36(1.20)$ & $43(1.40)$ & \\
\hline II & $1543(15.40)$ & 1018(16.40) & $525(13.80)$ & & 891(14.70) & 435(14.30) & $456(15.00)$ & \\
\hline III & $8236(82.30)$ & $5050(81.30)$ & $3186(84.00)$ & & $5054(83.20)$ & $2542(83.60)$ & 2512(82.70) & \\
\hline IV & $85(0.80)$ & $51(0.80)$ & $34(0.90)$ & & $54(0.90)$ & $26(0.90)$ & $28(0.90)$ & \\
\hline Stage $T$ & & & & $<0.001$ & & & & 0.583 \\
\hline 1 & $3059(30.60)$ & $1722(27.70)$ & 1337(35.30) & & $2037(33.50)$ & $996(32.80)$ & $1041(34.30)$ & \\
\hline 2 & $4900(49.00)$ & $3019(48.60)$ & $1881(49.60)$ & & $2988(49.20)$ & $1520(50.00)$ & 1468(48.30) & \\
\hline 3 & $1395(13.90)$ & $969(15.60)$ & $426(11.20)$ & & $772(12.70)$ & $383(12.60)$ & $389(12.80)$ & \\
\hline 4 & $652(6.50)$ & $505(8.10)$ & $147(3.90)$ & & $281(4.60)$ & $140(4.60)$ & $141(4.60)$ & \\
\hline Stage N & & & & $<0.001$ & & & & 0.002 \\
\hline 0 & $3059(30.60)$ & $1722(27.70)$ & $1337(35.30)$ & & $3307(54.40)$ & $1716(56.50)$ & $1591(52.40)$ & \\
\hline 1 & $4900(49.00)$ & $3019(48.60)$ & $1881(49.60)$ & & $1702(28.00)$ & 787(25.90) & $915(30.10)$ & \\
\hline 2 & $1395(13.90)$ & $969(15.60)$ & $426(11.20)$ & & $701(11.50)$ & $349(11.50)$ & $352(11.60)$ & \\
\hline 3 & $652(6.50)$ & $505(8.10)$ & $147(3.90)$ & & $368(6.10)$ & $187(6.20)$ & $181(6.00)$ & \\
\hline $\begin{array}{l}\text { Tumor } \\
\text { size(mm) }\end{array}$ & & & & $<0.001$ & & & & 0.234 \\
\hline$\otimes 20$ & $2765(27.60)$ & $1549(24.90)$ & $1216(32.10)$ & & $1843(30.30)$ & $894(29.40)$ & $949(31.20)$ & \\
\hline $20-50$ & $5490(54.90)$ & $3414(54.90)$ & $2076(54.80)$ & & $3321(54.60)$ & $1692(55.70)$ & $1629(53.60)$ & \\
\hline$\triangle 50$ & $1751(17.50)$ & 1252(20.10) & $499(13.20)$ & & $914(15.00)$ & $453(14.90)$ & $461(15.20)$ & \\
\hline
\end{tabular}




\begin{tabular}{llllllll}
\hline 0 & $6050(60.50)$ & $3532(56.80)$ & $2518(66.40)$ & $3782(62.20)$ & $1911(62.90)$ & $1871(61.60)$ \\
\hline $1-3$ & $2467(24.70)$ & $1592(25.60)$ & $875(23.10)$ & $1549(25.50)$ & $758(24.90)$ & $791(26.00)$ \\
\hline$\geq 4$ & $1489(14.90)$ & $1091(17.60)$ & $398(10.50)$ & & $747(12.30)$ & $370(12.20)$ & $377(12.40)$ \\
\hline Surgery type & & & & $<0.001$ & & & 0.979 \\
\hline $\begin{array}{l}\text { Radical } \\
\text { mastectomy }\end{array}$ & $4475(44.70)$ & $3147(50.60)$ & $1328(35.00)$ & & $2499(41.10)$ & $1249(41.10)$ & $1250(41.10)$ \\
\hline $\begin{array}{l}\text { Total } \\
\text { mastectomy }\end{array}$ & $5531(55.30)$ & $3068(49.40)$ & $2463(65.00)$ & & $3579(58.90)$ & $1790(58.90)$ & $1789(58.90)$ \\
\hline $\begin{array}{l}\text { Chemotherapy } \\
\text { No/unknown }\end{array}$ & $2121(21.20)$ & $1673(26.90)$ & $448(11.80)$ & & $807(13.30)$ & $389(12.80)$ & $418(13.80)$ \\
\hline Yes & $7885(78.80)$ & $4542(73.10)$ & $3343(88.20)$ & & $5271(86.70)$ & $2650(87.20)$ & $2621(86.20)$ \\
\hline Radiotherapy & & & & 0.053 & & & 0.273 \\
\hline No/unknown & $6869(68.60)$ & $4223(67.90)$ & $2646(69.80)$ & & $4040(66.50)$ & $2024(66.60)$ & $2016(66.30)$ \\
\hline Yes & $3137(31.40)$ & $1992(32.10)$ & $1145(30.20)$ & & $2038(33.50)$ & $1015(33.40)$ & $1023(33.70)$
\end{tabular}

Table 2. Cox proportional hazard regression model of breast cancer-specific survival $(n=6078)$ 
Univariate Cox

\begin{tabular}{|c|c|c|c|c|}
\hline Variables & $\mathrm{HR}(95 \% \mathrm{Cl})$ & $P$ value & $\mathrm{HR}(95 \% \mathrm{Cl})$ & $P$ value \\
\hline \multicolumn{5}{|l|}{ CPM } \\
\hline No & Ref. & & Ref. & \\
\hline Yes & $0.83(0.72-0.95)$ & 0.006 & $0.79(0.69-0.90)$ & 0.001 \\
\hline \multicolumn{5}{|l|}{ Age } \\
\hline$<40$ & Ref. & & Ref. & \\
\hline $40-59$ & $0.69(0.58-0.81)$ & $<0.001$ & $0.81(0.68-0.97)$ & 0.021 \\
\hline$\geq 60$ & $0.74(0.58-0.95)$ & 0.017 & $0.95(0.73-1.22)$ & 0.669 \\
\hline \multicolumn{5}{|l|}{ Race } \\
\hline White & Ref. & & Ref. & \\
\hline Black & $1.19(1.00-1.41)$ & 0.044 & $1.13(0.95-1.35)$ & 0.156 \\
\hline Other & $0.63(0.45-0.89)$ & 0.009 & $0.73(0.52-1.04)$ & 0.082 \\
\hline \multicolumn{5}{|c|}{ Marital status } \\
\hline Married & Ref. & & Ref. & \\
\hline Not Married & $1.26(1.10-1.44)$ & 0.001 & $1.14(0.99-1.31)$ & 0.062 \\
\hline \multicolumn{5}{|l|}{ Laterality } \\
\hline Left & Ref. & & & \\
\hline Right & $1.02(0.89-1.17)$ & 0.774 & & \\
\hline \multicolumn{5}{|l|}{ Grade } \\
\hline I & Ref. & & Ref. & \\
\hline II & $1.64(0.72-3.75)$ & 0.238 & $1.63(0.71-3.72)$ & 0.247 \\
\hline III & $2.27(1.01-5.06)$ & 0.046 & $2.00(0.89-4.49)$ & 0.093 \\
\hline IV & $3.96(1.52-10.31)$ & 0.005 & $3.42(1.31-8.95)$ & 0.012 \\
\hline \multicolumn{5}{|l|}{ Stage T } \\
\hline 1 & Ref. & & Ref. & \\
\hline 2 & $2.20(1.82-2.66)$ & $<0.001$ & $1.37(0.93-2.01)$ & 0.111 \\
\hline 3 & $5.28(4.27-6.52)$ & $<0.001$ & $1.97(1.18-3.31)$ & 0.01 \\
\hline 4 & $7.29(5.65-9.42)$ & $<0.001$ & $2.84(1.82-4.42)$ & $<0.001$ \\
\hline \multicolumn{5}{|l|}{ Stage N } \\
\hline 0 & Ref. & & Ref. & \\
\hline 1 & $2.69(2.27-3.18)$ & $<0.001$ & $0.98(0.67-1.43)$ & 0.911 \\
\hline 2 & $5.47(4.49-6.66)$ & $<0.001$ & $1.09(0.71-1.67)$ & 0.706 \\
\hline 3 & $9.29(7.56-11.42)$ & $<0.001$ & $1.79(1.16-2.75)$ & 0.009 \\
\hline \multicolumn{5}{|c|}{ Tumor size(mm) } \\
\hline$<20$ & Ref. & & Ref. & \\
\hline $20-50$ & $2.23(1.84-2.71)$ & $<0.001$ & $1.30(0.87-1.93)$ & 0.195 \\
\hline
\end{tabular}




\begin{tabular}{lllll}
$>50$ & $5.84(4.74-7.19)$ & $<0.001$ & $1.87(1.13-3.10)$ & 0.015 \\
\hline Regional nodes positive & & & & \\
\hline 0 & Ref. & & Ref. & \\
\hline $1-3$ & $2.62(2.22-3.10)$ & $<0.001$ & $2.35(1.64-3.37)$ & $<0.001$ \\
\hline$\geq 4$ & $7.10(6.03-8.36)$ & $<0.001$ & $4.43(3.00-6.54)$ & $<0.001$ \\
\hline Surgery type & & & & \\
\hline Radical mastectomy & Ref. & & Ref. & \\
\hline Total mastectomy & $0.46(0.40-0.53)$ & $<0.001$ & $0.97(0.83-1.13)$ & 0.683 \\
\hline Chemotherapy & & & & \\
\hline No & Ref. & & Ref. & \\
\hline Yes & $1.44(1.15-1.79)$ & 0.001 & $0.70(0.55-0.89)$ & 0.004 \\
\hline Radiotherapy & & & & 0.863
\end{tabular}

Table 3. Cox proportional hazard regression model of overall survival $(n=6078)$ 
Univariate Cox

\section{HR (95\% Cl)}

P value

CPM

\begin{tabular}{|c|c|c|c|c|}
\hline Variables & $\mathrm{HR}(95 \% \mathrm{Cl})$ & $P$ value & $\mathrm{HR}(95 \% \mathrm{Cl})$ & $P$ value \\
\hline \multicolumn{5}{|l|}{ CPM } \\
\hline No & Ref. & & Ref. & \\
\hline Yes & $0.78(0.69-0.88)$ & $<0.001$ & $0.74(0.66-0.84)$ & $<0.001$ \\
\hline \multicolumn{5}{|l|}{ Age } \\
\hline$<40$ & Ref. & & Ref. & \\
\hline $40-59$ & $0.71(0.60-0.84)$ & $<0.001$ & $0.83(0.70-0.98)$ & 0.032 \\
\hline$\geq 60$ & $0.96(0.78-1.20)$ & 0.74 & $1.17(0.93-1.47)$ & 0.172 \\
\hline \multicolumn{5}{|l|}{ Race } \\
\hline White & Ref. & & Ref. & \\
\hline Black & $1.18(1.00-1.38)$ & 0.045 & $1.13(0.96-1.33)$ & 0.132 \\
\hline Other & $0.60(0.44-0.84)$ & 0.002 & $0.71(0.51-0.99)$ & 0.045 \\
\hline \multicolumn{5}{|c|}{ Marital status } \\
\hline Married & Ref. & & Ref. & \\
\hline Not Married & $1.31(1.15-1.48)$ & $<0.001$ & $1.18(1.04-1.35)$ & 0.01 \\
\hline \multicolumn{5}{|l|}{ Laterality } \\
\hline Left & Ref. & & & \\
\hline Right & $1.00(0.88-1.13)$ & 0.959 & & \\
\hline \multicolumn{5}{|l|}{ Grade } \\
\hline I & Ref. & & Ref. & \\
\hline II & $1.33(0.67-2.61)$ & 0.416 & $1.34(0.68-2.65)$ & 0.397 \\
\hline III & $1.73(0.90-3.34)$ & 0.101 & $1.61(0.83-3.11)$ & 0.161 \\
\hline IV & $3.38(1.52-7.53)$ & 0.003 & $3.06(1.36-6.85)$ & 0.007 \\
\hline \multicolumn{5}{|l|}{ Stage T } \\
\hline 1 & Ref. & & Ref. & \\
\hline 2 & $2.03(1.71-2.41)$ & $<0.001$ & $1.23(0.88-1.74)$ & 0.23 \\
\hline 3 & $4.57(3.77-5.55)$ & $<0.001$ & $1.89(1.18-3.05)$ & 0.009 \\
\hline 4 & $6.38(5.04-8.08)$ & $<0.001$ & $2.60(1.73-3.90)$ & $<0.001$ \\
\hline \multicolumn{5}{|l|}{ Stage N } \\
\hline 0 & Ref. & & Ref. & \\
\hline 1 & $2.44(2.09-2.85)$ & $<0.001$ & $0.96(0.67-1.38)$ & 0.836 \\
\hline 2 & $4.80(4.00-5.76)$ & $<0.001$ & $1.04(0.70-1.57)$ & 0.836 \\
\hline 3 & $8.00(6.60-9.70)$ & $<0.001$ & $1.70(1.13-2.57)$ & 0.011 \\
\hline \multicolumn{5}{|c|}{ Tumor size(mm) } \\
\hline$<20$ & Ref. & & Ref. & \\
\hline $20-50$ & $2.11(1.77-2.51)$ & $<0.001$ & $1.43(1.00-2.03)$ & 0.048 \\
\hline
\end{tabular}

Multivariate Cox

Page 12/18 


\begin{tabular}{lllll}
$>50$ & $5.10(4.21-6.17)$ & $<0.001$ & $1.88(1.18-2.99)$ & 0.008 \\
\hline Regional nodes positive & & & & \\
\hline 0 & Ref. & & Ref. & \\
\hline $1-3$ & $2.42(2.07-2.82)$ & $<0.001$ & $2.31(1.64-3.24)$ & $<0.001$ \\
\hline$\geq 4$ & $6.31(5.43-7.34)$ & $<0.001$ & $4.31(2.98-6.23)$ & $<0.001$ \\
\hline Surgery type & & & & \\
\hline Radical mastectomy & Ref. & & Ref. & \\
\hline Total mastectomy & $0.49(0.43-0.56)$ & $<0.001$ & $0.97(0.84-1.12)$ & 0.706 \\
\hline Chemotherapy & & & & \\
\hline No & Ref. & & Ref. & \\
\hline Yes & $1.17(0.97-1.41)$ & 0.111 & $0.62(0.51-0.76)$ & $<0.001$ \\
\hline Radiotherapy & & & & 0.607
\end{tabular}

\section{Figures}

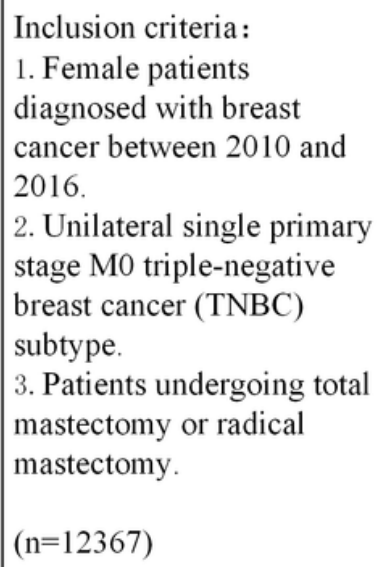

Exclusion criteria :

1.Unknown marital status

2.Unknown race recode

3.Unknown grade

4. Unknown AJCC T

5.Unknown AJCC N

6.Unknown radiation recode

7.Unknown chemotheraphy recode

8.Unknown tumor size

9.Unknown regional nodes status

10.Survival time less than 1 month

$(n=2361)$

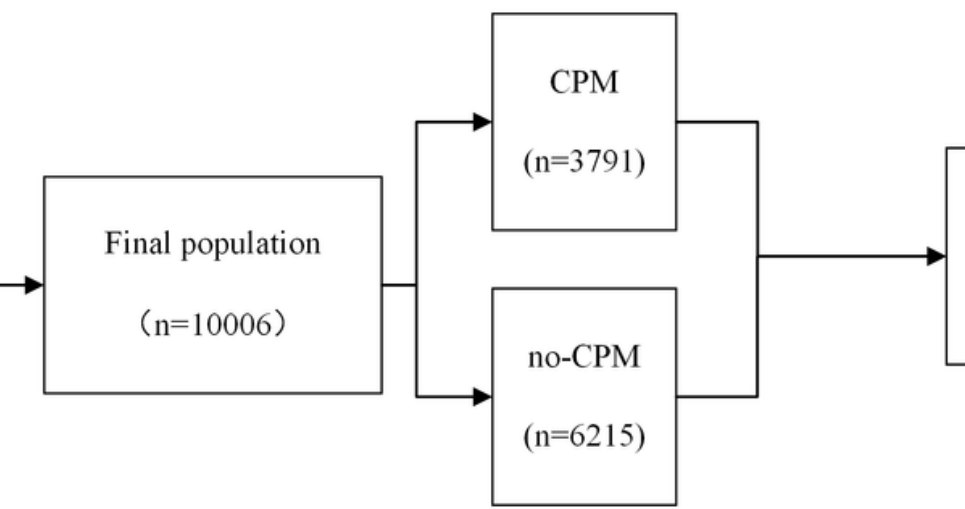

After PSM ( $n=3039$ pairs) 
A All population

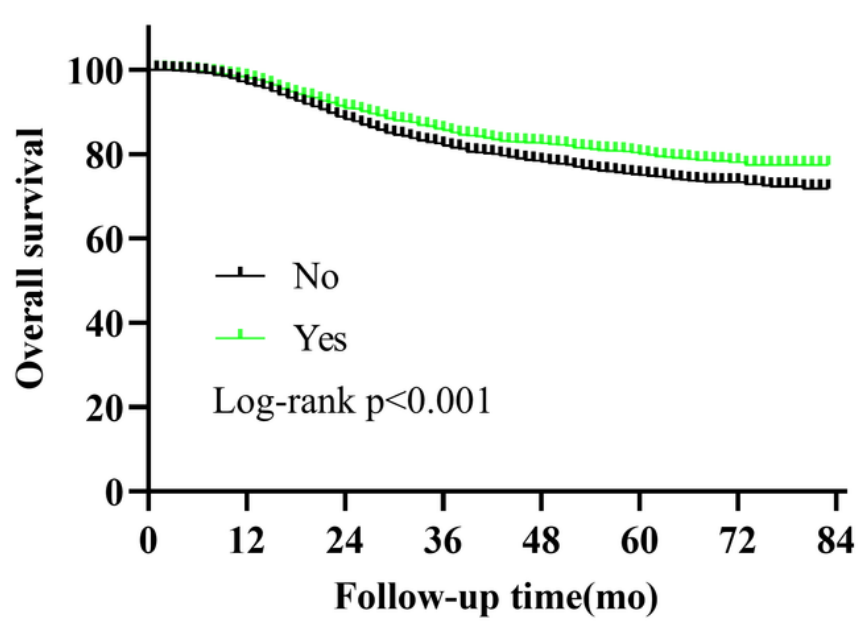

B All population

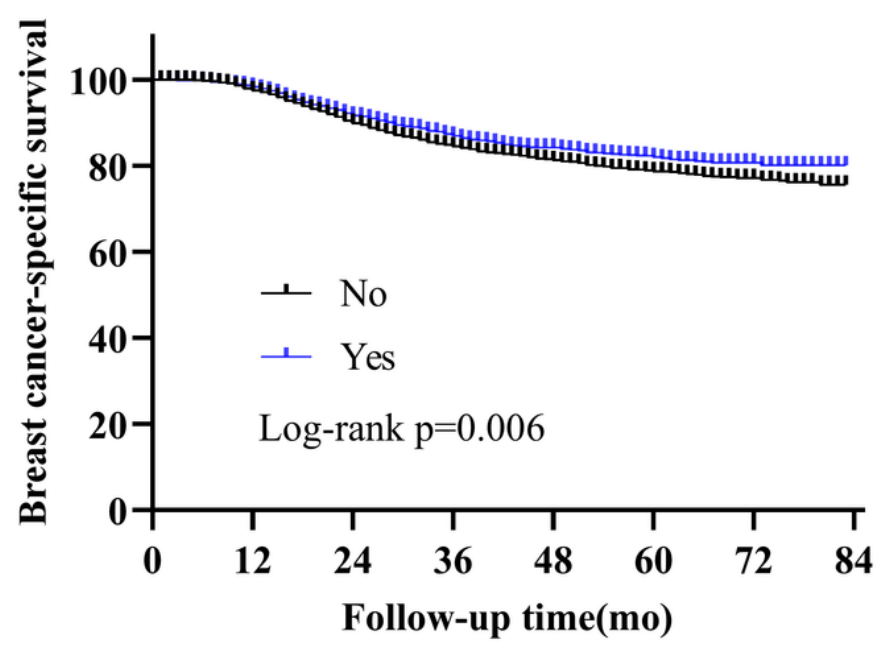

Figure 2

The flowchart of patients' selection from the SEER database 

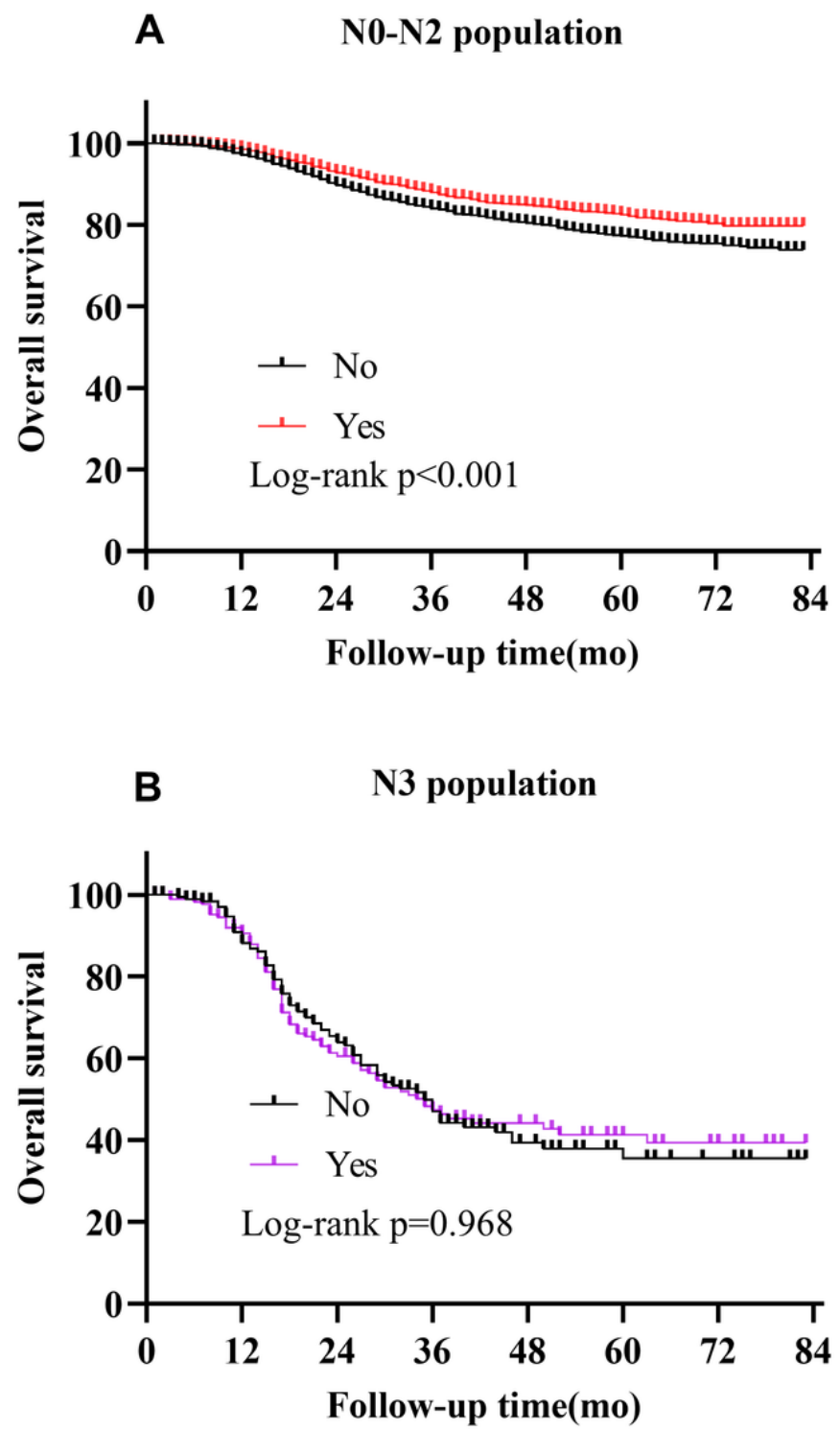

Figure 3

Survival curves with the log-rank tests of breast cancer-specific survival for N0-N2 population (A), N3 population (B) 


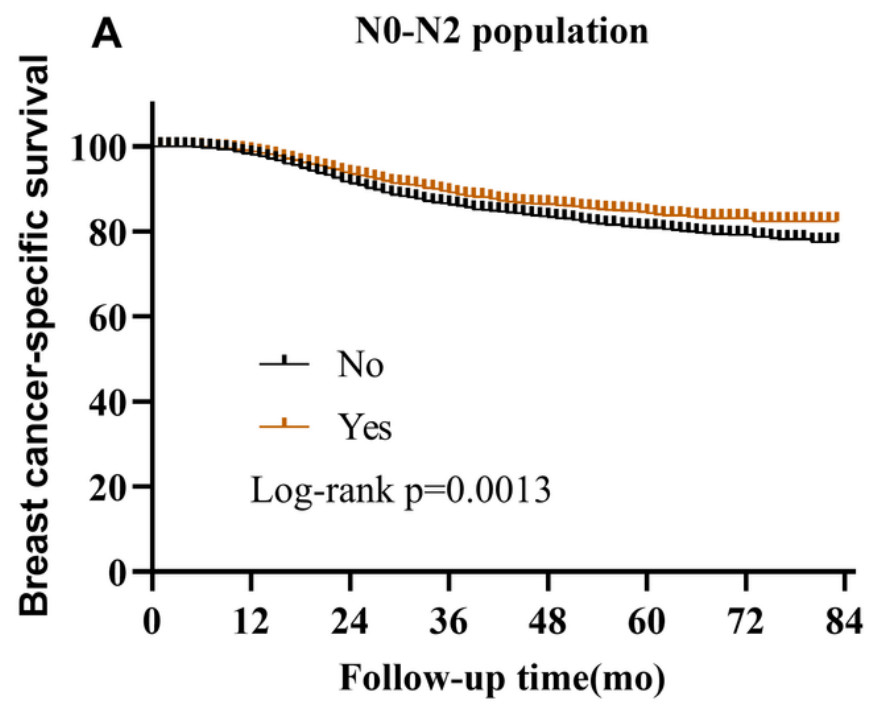

B N3 population

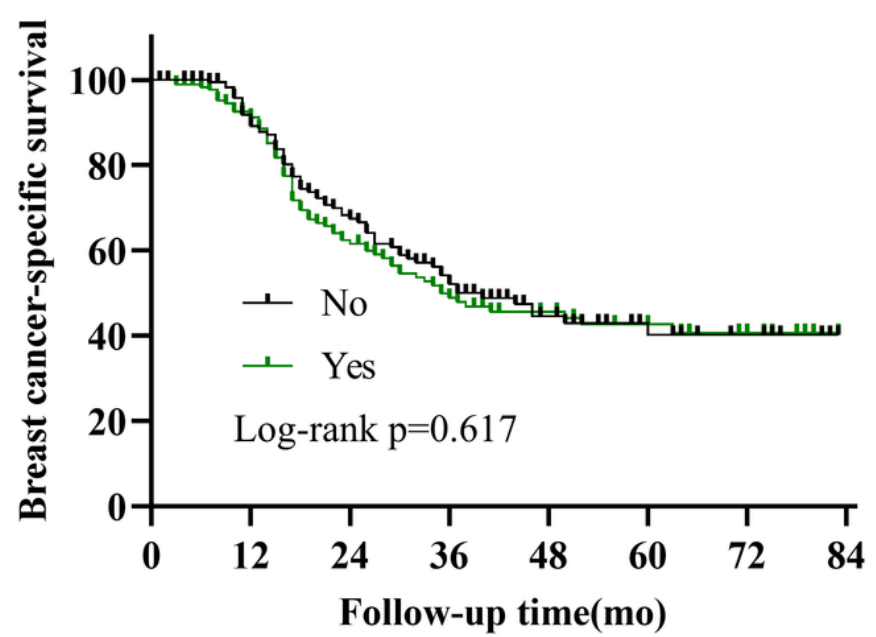

Figure 4

Survival curves with the log-rank tests ofoverall survival for N0-N2 population (A), N3 population (B) 


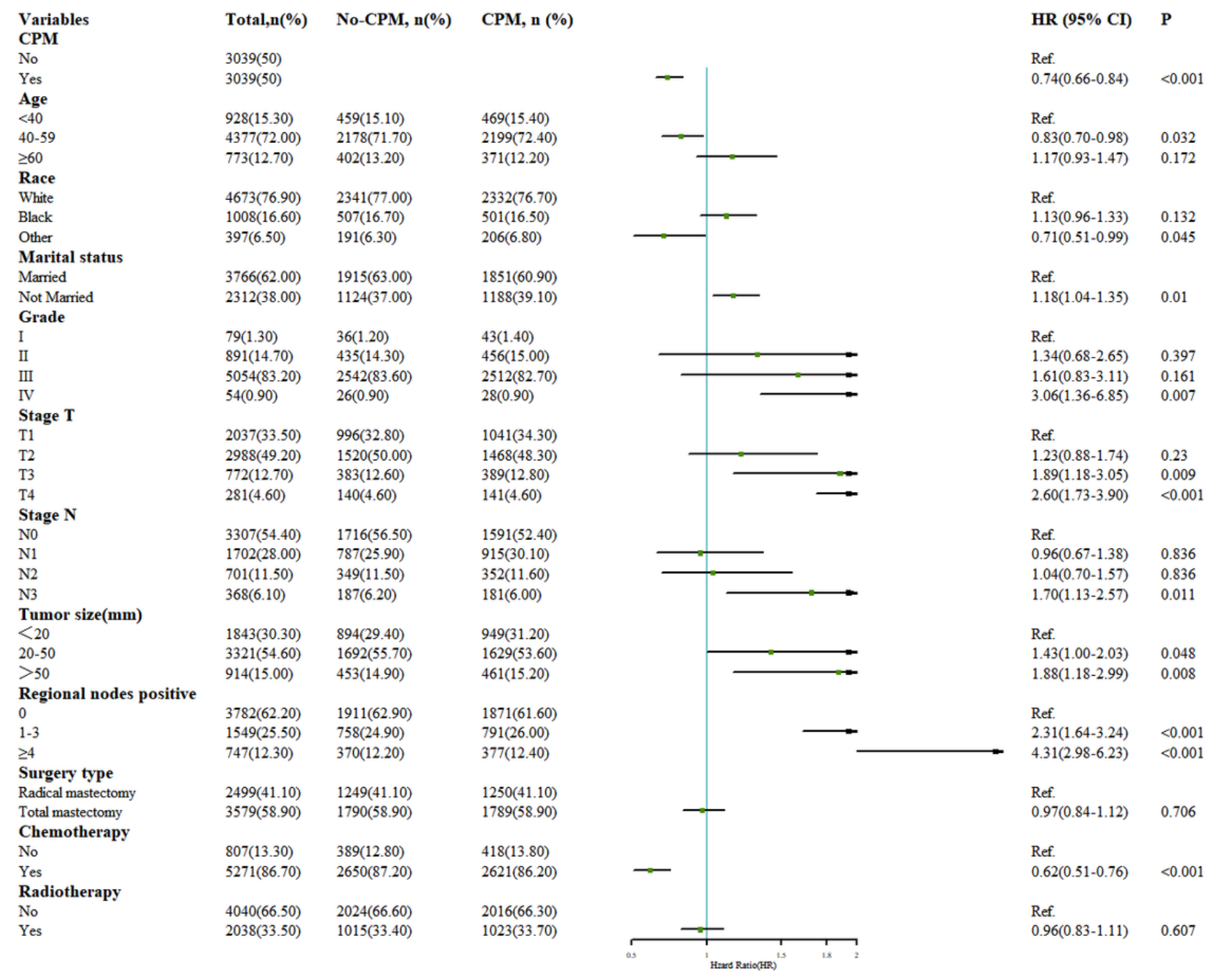

\section{Figure 5}

Forest plot of hazard ratios (HRs) of OS for contralateral prophylactic mastectomy (CPM) group versus non-contralateral prophylactic mastectomy (no-CPM) group in the subgroup analysis. 


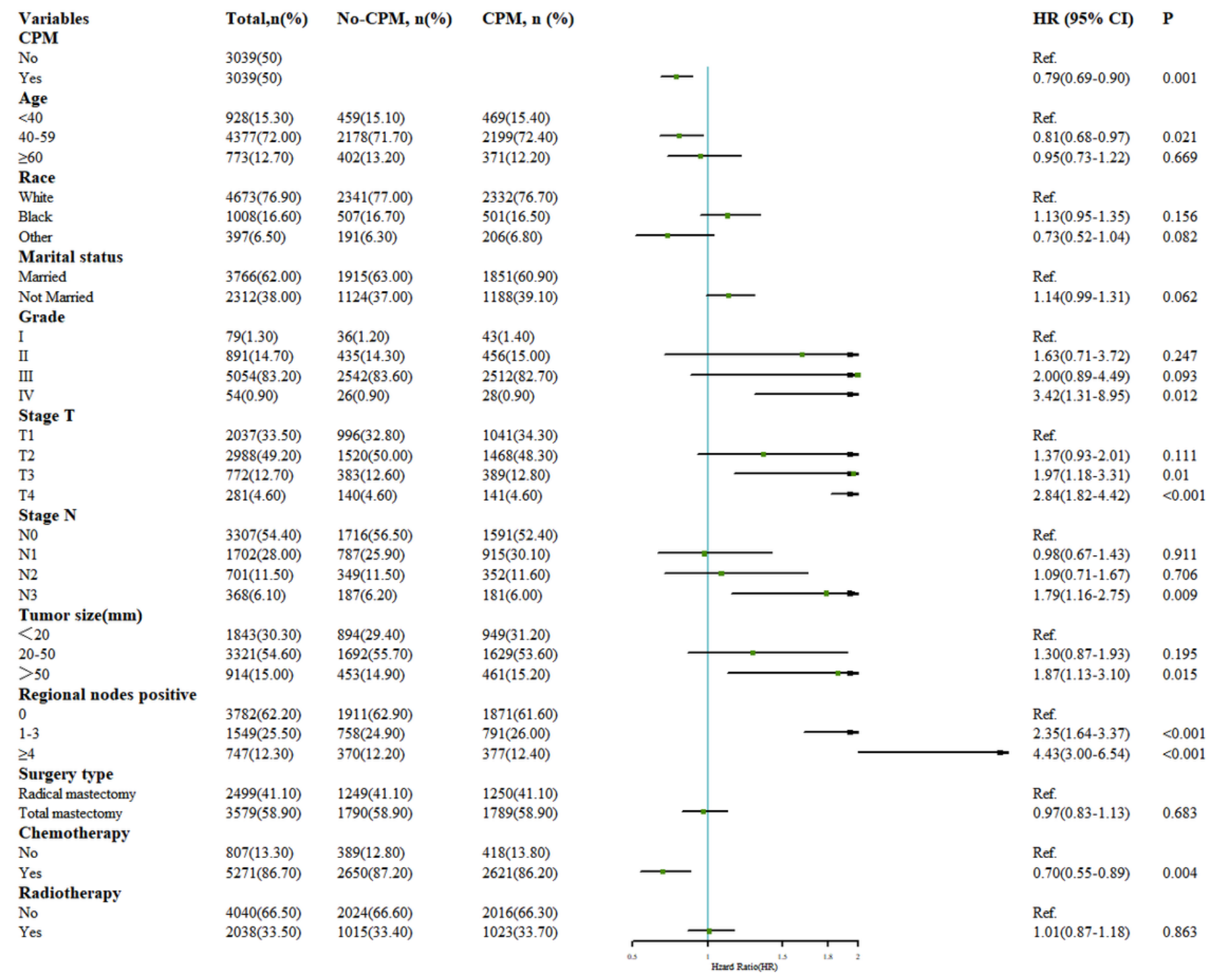

\section{Figure 6}

Forest plot of hazard ratios (HRs) of BCSS for contralateral prophylactic mastectomy (CPM) group versus non-contralateral prophylactic mastectomy (no-CPM) group in the subgroup analysis. 